\title{
Zhu Xi's influence on Song and Yuan calligraphy
}

\author{
Weiwei Qin ${ }^{1}$ Hongwei $\mathrm{Si}^{1} \quad$ Yun $\mathrm{Chen}^{1 *}$ \\ ${ }^{1}$ Institute of Architecture and Environment Art, Shanghai Urban Construction Vocational College, Shanghai, 201415, \\ China \\ *Corresponding author's e-mail: chenyun@succ.edu.cn
}

\begin{abstract}
This paper provides an in-depth analysis of Zhu Xi's thought on calligraphy and fully explains the influence of Zhu Xi's calligraphy on the thoughts and works of calligraphers in the Song and Yuan dynasties. Zhu Xi's thoughts on calligraphy, such as Fagu, Changli, Daotong, and Yazheng have been shown in the works of many later generations of calligraphers. The Song dynasty's Wei Liaoweng and the Yuan dynasty's Zhao Mengfu all drew from Zhu Xi's theories and practices. Zhu Xi's ideas on calligraphy are in line with the ethical and moral as well as ruling order concerns of today's society, and are conducive to the cultivation of an ideal personality and the spirit of moral self-discipline today.
\end{abstract}

Keywords: Zhu Xi, Song and Yuan calligraphy, influence

\section{INTRODUCTION}

After Confucius, Zhu Xi was a famous educator and thinker in China's history, and a great master of the Song Dynasty. In the Yuan Dynasty, Tao Zongyi's "The History of Calligraphy" states: " Zhu Xi inherited the doctrine of Taoism, as a generation of sages, not only is the doctrine even calligraphy is also reached a great state. Good at cursive, especially good at large characters, under the pen that is calm and elegant, his works, even if they are very small, are highly prized and everyone is clamoring to buy them at very high prices. [1]" It can be seen that Zhu Xi's calligraphy is extremely well known at that time and even in later generations. Zhu Xi's calligraphy on Fagu, Changli, Daotong, Yazheng and other ideas have been in the works of many later generations of calligraphers have shown.

\section{PATHWAYS OF ZHU XI'S INFLUENCE ON SONG AND YUAN CALLIGRAPHY}

\subsection{Zhu Xi's Ideas on Calligraphy}

As a rationalist, Zhu Xi learned from the "Luo school" of Cheng Yi and Cheng Hao, with Taoism as the main body, and attached importance to the practice of calligraphy. His calligraphy seeks the law, emphasizing that " As an art, calligraphy can reflect the level of knowledge of the calligrapher to a certain extent. "; at the same time, he advocates "Not purposely pursuing the law and not departing from it", and "the heart of the wonders of the self can be realized", all of which profoundly influenced the Southern Song Dynasty after the All these have profoundly influenced the calligraphy world after the Southern Song Dynasty.

Zhu Xi's calligraphic thinking was based on Fagu, Changli, Daotong, and Yazheng, and Zhu Xi was able to achieve such attainments in calligraphy, largely because he was able to "Respect for teachers and learning from the ancients". He was a great admirer of the calligraphers who sought the law of reason and law, while disparaging the novelty. He admired the calligraphy of Cai Xiang, Ouyang Xiu, and Sima Guang, Shao Yong, and Zeng Gong, which met his ideological requirements and aesthetic standards. On the whole, Zhu Xi did not appreciate or approve of the interjection and indulgent calligraphy of the Calligraphy.

Zhu Xi in calligraphy also adhere to the style of simplicity, opposed to deliberate artifice, flashy style. "Wen Dao Tong Yi" is the main idea of Zhu Xi calligraphy theoretical thought. From the examination of his calligraphy and manuscripts, not only is there no legacy of Han and Wei, but the style of the times and his own characteristics are particularly strong [2]. The "style of the times" referred to here is "Shang Yi", that is, " "Not purposely pursuing the law and not departing from it, really said that one by one from their own chests flow [3]." In the Song Dynasty, the calligraphic style was so prevalent that some people simply ignored the traditional legal system, but Zhu Xi set the highest standard for calligraphic creation and criticism with his own creative actions and calligraphic thoughts, namely, "one by one, 
from his own heart". Zhu Xi 's admiration for the ancient style, his emphasis on legalism, his admiration for the sages and scholars of the Northern Song Dynasty, his criticism of the extreme style of calligraphy, and his advocacy of a calligraphic style that is gentle and harmonious, in keeping with the way of the sages, are all realistic warnings for the Southern Song and even for today's calligraphic world.

Zhu Xi's philosophy, so that the book theory towards profound and simple, pay attention to the book character and character, especially focus on the ethical and moral content of the book theory, this focus on the book character and character of the combination of the book theory mode, has had a huge and far-reaching impact on future generations.

\subsection{Zhu Xi's calligraphy works}

As a calligrapher who has long been nourished in learning, Zhu Xi's image is full and clear. Some of Zhu Xi's works, on the one hand, created a variety of calligraphy, on the other hand, has a clear aesthetic view of calligraphy, from Zhu Xi's "Hui An Ti Ba" is visible in its early and mid-century are very appreciative of the calligraphy of the great scholars. For example, "Feng Tong Zhang Jing Fu Cheng Nan Er Shi Yong Shi Juan" in the south of the city clearly shows a kind of "Wei-Jin style".

Zhu $\mathrm{Xi}$ in his later years, whether in learning or technical work, have reached a considerable level, this period to establish a correct understanding of calligraphy and comprehend the highest level of calligraphy has become inevitable. Zhu Xi in his later years, "Shen Qiu Tie ", "Shu Han Wen Gao Juan" and other calligraphic works can be seen, his calligraphy works both Tang law Jin rhyme, and Song meaning of the subtlety. At this time, $\mathrm{Zhu} \mathrm{Xi}$ in the calligraphy of the enlightened, realized that the supreme state of calligraphy is "such as the chest in a different way, that is, moving around in the ritual" [4]. This period of Shu Han Wen Gao Juan "reflects Zhu Xi's calligraphic achievements and calligraphic realm - both extremely rich in the characteristics of the times and personal color.

\section{ZHU XI'S INFLUENCE ON SONG AND YUAN CALLIGRAPHY}

\subsection{Influence on the Ideology of Song and Yuan Calligraphers}

Wei Liaoweng, the most famous rationalist at the end of the Song Dynasty, was after Zhu Xi and Lu Jiuyuan, and he was eclectic between $\mathrm{Zhu}$ and $\mathrm{Lu}$, but inclined to the heart. As a rationalist, like Zhu Xi, Wei Liaoweng also advocated that "the heart is correct then the pen is correct". Overview of Wei's book theory, neither radical words, nor extreme views, from which the shadow of $\mathrm{Zhu} \mathrm{Zi}$ can be seen. Wei Liaoweng's theory of calligraphy in the inheritance of Zhu Zi's study, one is to discuss the book with people, the book character and human character closely combined, pay attention to the calligrapher's personality quality; two is the "law" and "escape" combined, emphasizing the "meaning" of the external expression, full of dialectical thinking. Thirdly, it is the view of the Dao of calligraphy that "calligraphy flows from the Dao ", which agrees that the Tao and the art are one, but the Tao contains the art. These three points form the main characteristics of his theory of calligraphy [5].

As a scholar, Hao Jing was proficient in calligraphy and painting and wrote many books, including "Hao Wen Zhong Gong Ji" and" Ling Chuan Ji". Hao Jing advocated that the Way is the essence of technique, and that calligraphy as "technique" fully reflects the Way. Hao Jing's "Dao" not only refers to the aforementioned laws of calligraphy development, but also covers the moral standards of being a human being, thus coinciding with Zhu Xi 's claim that " As an art, calligraphy can reflect the level of knowledge of the calligrapher to a certain extent. ", from which we can see his Confucian position. In addition, Hao Jing also advocated the use of the past as a basis for calligraphy, suggesting that calligraphy should be learned from the source. It is evident that Hao Jing's approach to the ancient world is similar to $\mathrm{Zhu} \mathrm{Xi}$ 's idea of the ancient world.

Zhao Mengfu's calligraphy is the same as Zhu Xi 's " As an art, calligraphy can reflect the level of knowledge of the calligrapher to a certain extent. ". Zhao Mengfu was a great calligrapher and painter of his generation, with many handwritten works. The Yuan dynasty revered the doctrine of Zhu Xi, and the Yuan calligraphers, led by Zhao Mengfu, practiced and developed Zhu Xi's calligraphic ideas. Although the early Yuan dynasty's ideology was still fragmentary in its expression in calligraphy, in the late Yuan dynasty, Zheng Qiao, a famous calligrapher of the Yuan dynasty, systematized the theory of calligraphy with the birth of "Yanji", thus completely systematizing Zhu Xi's calligraphic thought.

The "reason" and "way" of Zhu Xi's calligraphy are the first elements of Zheng Qiao's calligraphic criticism. The influence of Zhu Xi's thought on Yuan calligraphy was profound, and the calligraphers, led by Zhao Mengfu, could be said to be the practice of Zhu Xi's calligraphy.

\subsection{Influence on Song and Yuan Calligraphic Works}

View Zhu Xi [6] "Feng Tong Zhang Jing Fu Cheng Nan Er Shi Yong Shi Juan", and "Yu Yan Xiu Wei Fu Tie", "Lun Yu Ji Zhu Can Gao" and Wei Liaoweng, Hao Jing, Zhao Mengfu, etc. [7] "Wen Xiang Tie Juan", "Xiang Wang Tie", "Zhi An Dao Shi Lang Chi Du" and other works, we can easily find Zhu Xi on the structure of the calligraphy works of the Song and Yuan dynasties, the 
influence on the chapter (Table 1).

Table 1 Comparison of Zhu Xi's calligraphic works with those influenced by him

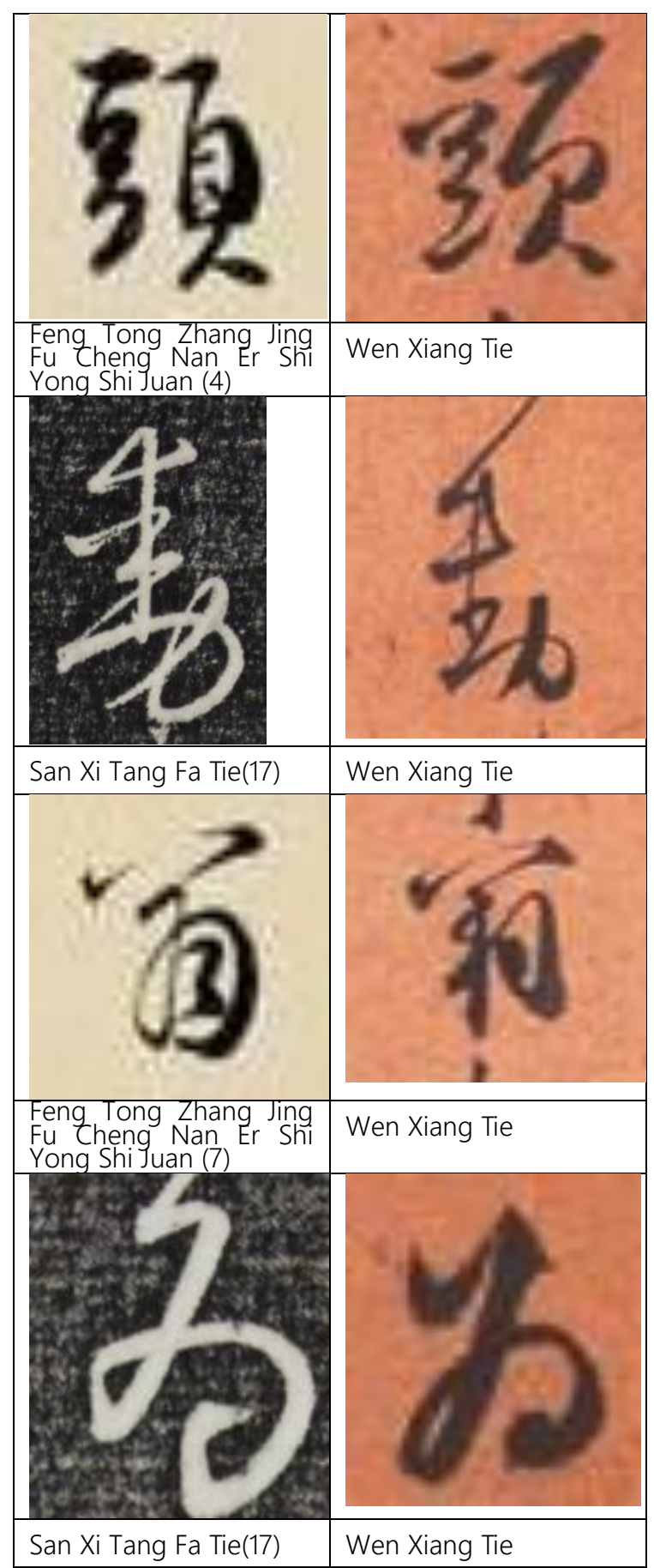

The following is an analysis of the brushwork and style of $\mathrm{Zhu} \mathrm{Xi}$ and the calligraphers of the Song and Yuan dynasties: " Feng Tong Zhang Jing Fu Cheng Nan Er Shi Yong Shi Juan (Figure 1)" is one of Zhu Xi's best preserved works. The brushwork is predominantly openedged, and the calligraphic style gives the world a strong, heavy, broad and generous feeling.

The work of Song and Yuan calligraphers is the best example of Zhu Xi's calligraphy, and the style of his work also inherits the characteristics of Zhu Xi's calligraphy, turning round and heavy, whether from the work of a point of painting, or turning and strokes are in line with Zhu Xi's style of calligraphy.

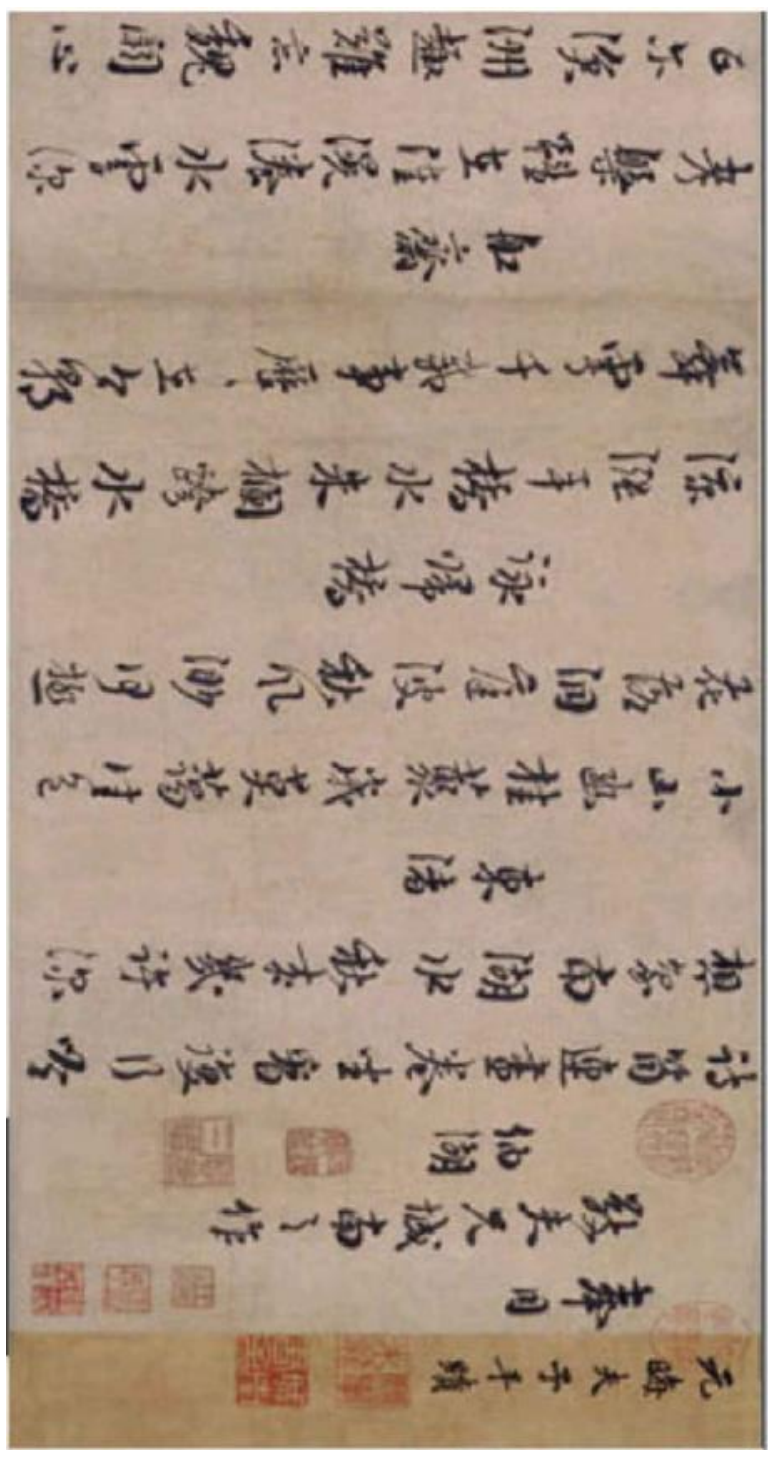

Figure 1 Feng Tong Zhang Jing Fu Cheng Nan Er Shi Yong Shi Juan (From The Forbidden City)

\section{CONCLUSION}

The author provides examples to demonstrate the influence of Zhu Xi on Song and Yuan calligraphy. Zhu Xi's ideas on calligraphy, such as Fagu, Changli, Daotong, and Yazheng, have been shown in the works of many calligraphers of the Song and Yuan dynasties, such as Wei Liaoweng, Hao Jing, and Zhao Mengfu, whose calligraphic ideas were clearly followed by Zhu Xi 's calligraphic criticism, forming a unique landscape in China's late feudal society. This is a unique landscape in the literary theory of late feudal society.

In today's calligraphic world, where popular calligraphic styles abound and cultural cultivation is lacking, Zhu Xi 's calligraphic thought provides us with wisdom and nourishment, which is conducive to the 
cultivation of ideal personality and moral self-discipline, and the healing effect of Zhu Xi 's theory of calligraphy is definitely beneficial to the simplification of the calligraphic world today.

\section{ACKNOWLEDGMENTS}

This paper is supported by the first-class higher vocational (professional) construction project "first-class professional construction of cultural relics restoration and conservation" (project number: YZ-2019-A) funded.

\section{REFERENCES}

[1] (Yuan) Tao ZY. (1984) Shu Shi Hui Yao, Shanghai: Shanghai Bookstore.

[2] Yang RK. (1997)"Zhu Xi's "Shu Han Manuscript" of the Southern Song Dynasty", Calligraphy Series, 2.

[3] Wang RM, Zhang QM. (1992) "Zhu Xi Collection", Volume 84, "Ten Tun Post", Ba Shu Shu She, 4322.

[4] Li JD. (1988)"Zhu Zi Shu Shu", vol. 140, "Essays", China Book Bureau, 3337.

[5] Qiu SH. (2007) "An Experiment on the Duality of Zhu Xi's Theory of Calligraphy and its Value", Journal of Nanjing Art Institute (Art and Design Edition), 2.

[6] Wuyishan Zhu Xi Research Center. (2005) Selected Calligraphy of Zhu Xi, Fujian Fine Arts Publishing House, 2005.

[7] Jin TD. (1995) A Great View of Chinese Authentic Works (Song and Jin), Cultural Relics Press. 